\title{
Cytochrome C Oxidase Subunit-1(COX1) Gene in Tilapia (Oreochromis Niloticus): its Cloning and Characterization
}

\author{
Iman M. K. Abumourad
}

Department of hydrobiology, National Research Center, Cairo, Egypt

\begin{abstract}
The current study aimed to identify cytochrome c oxidase subunit 1 (ONCOX1) in Tilapia (Oreochromis niloticus) immunized by formalin-killed Flavobacterium columnarae. Suppressive subtractive hybridization (SSH) was utilized to construct a cDNA library and a semi-quantitative RT-PCR analysis used to examine Oreochromis niloticus cytochrome $\mathrm{c}$ oxidase subunit 1 (COX1) gene expression. The complete sequence of the COX1 has been deposited in the GenBank Database and assigned the accession number (GE647880). COX1 cDNA is composed of 1139 bps with a 1107 bps open reading frame, the predicted gene product is 369 amino acid with molecular weight of $40.16 \mathrm{kDa}$. The amino acid sequence revealed high identity with subunit 1 from Oreochromis mossambicus. Compared to $\beta$-actin, the semi-quantitative RT-PCR revealed that ONCOX1 expressed in tissues of stimulated fish as up-regulated gene suggesting that this member of COX genes is probably involved in the general immune response against the pathogenic bacteria.
\end{abstract}

Keywords Tilapia, Cytochrome C Oxidase, Gene Expression, Protein Characterization

\section{Introduction}

Cytochrome $\mathrm{c}$ is a small, highly conserved, heme- containing bifunctional protein; it has been studied extensively, not only for its role in electron transport, but also for its role in apoptosis, it releases from the mitochondria in response to specific apoptotic stimuli (Wang X., 2001). Cytochrome c oxidase $(\mathrm{COX})$ is an oligomeric enzymatic complex located in the inner membrane of mitochondria which is consists of three large primarily catalytic subunits encoded by the mitochondrial genome and 10 smaller subunits encoded by nuclear genes.The nuclear encoded subunits are thought to modulate enzyme function. In vertebrates, $\mathrm{COX}$ is composed of 13-subunits, and a further 30 proteins are required for proper COX assembly (Ettickan et al, 2004). In eukaryotes this enzyme complex is located in the mitochondrial inner membrane. It is considered to be a major site of regulation of mitochondrial oxidative phosphorylation. This rate-limiting enzyme is also implicated in the production of reactive oxygen species (ROS) under oxidative stress conditions (Lee et al, 2001, 2003 and Vijayasarthy et al., 2003). COX1 encodes an important enzyme involved in the oxidation phosphorylation pathway and thus energy production. In an attempt to characterize differential gene expression during cDNA library construction from tilapia immunized by $F$. columnarae, we could recognize ONCOX1 as up-regulated

\footnotetext{
* Corresponding author:

imankam_2@yahoo.com (Iman M. K. Abumourad)

Published online at http://journal.sapub.org/ijge

Copyright (C) 2011 Scientific \& Academic Publishing. All Rights Reserved
}

gene. The specific hypothesis for this study is that gene characterization and detectable changes in gene expression directed by certain pathobiological conditions may identify genetic information that are important for understanding the host-pathogen relationship and host immune responses., thus in this paper we summarize the identification of a cytochrome $c$ oxidase subunit 1 gene utilizing available protein structure prediction methods based on the predicted protein sequence. The sequence we have identified and its predicted corresponding structure is the first functional annotation for this family of proteins in O.niloticus.

\section{Material and Methods}

\section{Tissue preparation and RNA extraction}

Oreochromis niloticus 12 individuals were obtained from Wuhan, China. The fish were held in the laboratory, acclimatized in recirculating freshwater tank at room temperature under natural photoperiod for a week and fed with commercial pellets at a daily ration of $3 \%$ of their body weight. They were devided into two groups, the first were stimulated for four days each with intraperitonial injection of0.5 $\mathrm{ml} 10^{7}$ formalin killed Flavobacterium columnarae, the other group were injected with PBS and used as a control. Two F.colmnarae injected tilapia, $24.5 \mathrm{~cm}$ and $27 \mathrm{~cm}$ in fork length were dissected, gills, liver; spleen, head kidney and intestine were dissected out for the construction of the infected group subtracted cDNA library. One control (PBS injected fish) $23.7 \mathrm{~cm}$ in fork length was used also for the subtracted library with the mentioned organs dissected out. Total RNA was prepared for RT-PCR using Trizol Reagent 
(Invetrogen, USA). The mRNA was then isolated from total RNA using the poly Atract Isolation System (Promega). Concentration of mRNA was determined using a spectrophotometer.

\section{SMART cDNA synthesis and Suppressive subtraction hybridization (SSH)}

Complimentary DNA was synthesized andamplified using a CLONTECH cDNA Synthesis Kit by following the the manufacure's instruction. The mRNA obtained from tester and driver samples was subjected to SSH and selective PCR amplification using PCR-select cDNA subtraction kit to construct a cDNA library.

\section{Cloning and screening for differential expression by dot} blotting and sequence analysis

secondary PCRs products of stimulated and unstimulatd directly inserted into pGEM-T using a pGEM-T Easy Vector System ( Promega), which was then transformed into Escherichia coli and screened by the white colonies which were selected and amplified with nested PCR primer 1(5'-TCGAGCGGCCGCCCGGGCAGGT-3') and nested PCR primer 2(5'- AGGGTGGTCGCGGCCGAGGT-3'). 3 $\mu l$ of PCR product were denatured in $3 \mathrm{ml}$ of $0.5 \mathrm{M} \mathrm{NaOH}$. Two identical H-bond $\mathrm{N}^{+}$nylon membranes were prepared by loading $1 \mu 1$ of denatured PCR product of each clone on the same location, after $5 \mathrm{~min}$. neutralization in $0.5 \mathrm{M}$ Tris-Hcl ( $\mathrm{pH} 7.5)$, the membranes were baked for $30 \mathrm{~min}$ at $120^{\circ} \mathrm{C}$ to cross link the cDNAs.

Forward-subtracted cDNAs were digested with Rsa1 and labeled as probes with digoxigenin using a DIG High Prime system (Boehringer Mannheim) by following the manufacture's instruction. Positive clones were sequenced using dedoxy chain sequencer (ABI Applied Biosystems Model 337).

\section{Sequence and phylogenetic analysis}

Sequences were compared with the sequences in the database using the BLASTX program at the web server of the National biotechnology information. Protein prediction was performed using software at the ExPASY Molecular Biology Sever (http:/expasy.pku.edu.cn) and SAPS program (Statistical Analysis of Protein Sequences). Sequences were aligned, employing the distance matrix; a distance-joining tree was constructed and a Phylogenetic analysis was carried out for the deduced amino acid sequences of cytochrome $\mathrm{c}$ oxidase subunit 1(COX1) using Clustal W version 1.83(Thompson et al. 1994), Sequence database alignments and comparisons were done with the BLAST family of programs (blastx,) against database specifications of non-redundant protein, SWISS-PROT which were available from the BLAST website at the National Center for Biotechnology Information webserver, (http://www.ncbi.nlm. nih. gov/ blast/) (Altschul et al. 1997). A signal peptide was predicted using Signal P 3.0 and analysis for transmembrane helices was applied using SOSUI dumbbell server.

Semi - quantitative RT - PCR for tissue expression of COX1
Total RNA from different mixed tissues was treated with DNase, $2 \mu \mathrm{g}$ RNA was reverse transcribed with M-MLV reverse transcriptase using hexanucleotides (Promega) to prim the reaction. The first strand cDNA was used as templates for RT-PCR with a pair of COXI specific primers designed, forward 5'- TTGGACACCCTGAAGT-3' and reverse: 5' GTGGCGGAAGTAAAGT3'.

The PCR cycling parameters were one cycle of $94^{\circ} \mathrm{C}$ for 5 min, 35 cycles of $94^{\circ} \mathrm{C}$ for $30 \mathrm{~s}, 48^{\circ} \mathrm{C}$ for $30 \mathrm{~s}$ and $72^{\circ} \mathrm{C}$ for 1 min, with a final extenssion step of $72^{\circ} \mathrm{C}$ for $10 \mathrm{~min}$. The RT-PCR products were analyzed by electrophoresis on $2 \%$ agarose gel with PCR products derived from beta actin of the infected and non infected tilapia as controls, documented with documentation system. Semi-quantitative assessment of mRNA levels were determined by quantifying the band's intensity of PCR products using GeneTools in the gene expression relative to beta actin were tested between infected and uninfected fish using t-test.

\section{Results}

\section{Isolation of differentially expressed clones}

The comparison of pooled RNA samples from Oreochromis niloticus immunized by Flavobacterium columnarae against unimmunized healthy Oreochromis niloticus yielded multiple differentially expressed clones; some were suggested as up-regulated genes in the process of immunization as revealed by dot blot analysis and RT-PCR.

\section{Characterization of cDNA sequence of ONCOX1}

The complete sequence of the COX1 has been deposited in the GenBank Database (http://www.ncbi.nlm.nih.gov/ Genbank/) and was assigned the GenBank nucleotide accession number (GE647880). Blast queries of the sequenced nucleotides of COX1 demonstrated that the deduced amino acid sequence contains 1139 nucleotide bps with 1107 bps open reading frame coding for a protein of 369 aa and molecular weight 40.16 kda (Fig. 1).

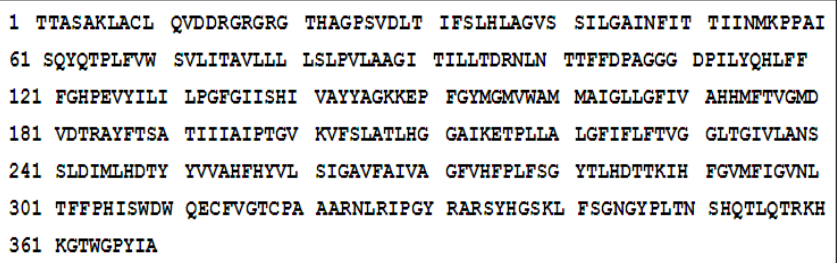

Figure 1. Deduced amino acid sequences of ONCOX1

\section{Protein structure prediction}

Through search of available sequence databases showed that the putative ONCOX1 sequence is homologous to other known cytochrome c oxidases with varying levels of sequence identity and high similarity with Oreochromis mossambicus (accession no.YP_272017) and also to human (accession no.BAA07292) and several vertebrates COX1. A signal peptide was predicted using Signal P 3.0, deduced amino acids analysis confirmed that this sequence has no signal peptide, the signal peptide probability $=0.026$, signal 
anchor probability: 0.126 and the max cleavage site probability: 0.017 between bps 44 and 45 . Average of hydrophobicity $=0.582114$. The revealed isoelectric point $(\mathrm{pI})$ of ONCOX $1=9.51$.

Multiple methods of transmembrane prediction were used to enable a consensus confirmation of predicted transmembrane helices. The TM region search for ONCOX1 by SOSUI analysis program beta version suggests that ONCOX1 is a membrane protein with 8 transmembrane helices(TM). Transmembrane helices were found in the positions 29-53,72-95, 126-145, 152-171, 192-211, 218-237, 258-282 and 289-306 as showed in table 1 .

\section{Alignment analysis and phylogenetic tree construction}

A Basic Genebee ClustalW 1.83 was performed on a variety of Cox1 genes from Engraulis japonicas; Pylodictis olivaris; Homo sapiens; Mus musculus; Oreochromis mossambicus and Oreochromis niloticus (accession nos. NP_203729; AAL91550; BAA07292; CAD54434; YP 272017 and GE647880 respectively). Fig.1. Oreochromis niloticus shares an overall identity of 89.2 - $99 \%$ with other known vertebrates. Using the Clustal $\mathrm{W}$ and the GeneBee programs, a phylogenetic tree was generated (Fig.2, 3).

\section{Expression of HSP9 in Oreochromis niloticus}

ONCOX1 expression studied by RT-PCR in mixed tissues from infected and uninfected control fish was detected only in the infected tilapia (Fig.4).

\section{Discussion}

Suppression subtractive hybridization (SSH) has led to the enrichment of specific expression genes as the non-specific expression of beta actin was reduced to about $2^{15}$ time lower after subtraction, suggesting that non-specific expressed genes have been avoided and immunization- specific genes have been enriched efficiently in this study. The identification of new genes involved in the bacterial immunization provides the foundation for further research on the immunoilogical interaction between host and the bacteria, In this study, cDNA library construction in case of $O$. niloticus immunized by $F$. columnarae introduced some new immune genes, one of them was ONCOX1.

dynamic change in an environment, disease hazards and the host-pathogen relationship provided signals for identifying differentially expressed genes which may play an im- portant role in the immune system responses. During construction of cDNA library from $O$. niloticus immunized by $F$. columnarae, we could identify and characterize cytochrome c oxidase subunit 1 gene as up-regulated gene.

ONCOX1 sequence was found to be homologous to other known cytochrome c oxidases with varying levels of sequence identity and high similarity with Oreochromis mossambicus (accession no.YP_272017) and also to human (accession no.BAA07292) and several vertebrates COX1, it appears to have structural features similar to the largest subunit of the heme/copper-requiring cytochrome c.

The prediction of O-GalNAc (mucin-type) for glycosylation sites in ONCOX1 proteins indicated the absence of any glycosylation sites. Multiple methods of transmembrane prediction were used to enable a consensus confirmation of predicted transmembrane helices. The TM region search for ONCOX1 by SOSUI analysis program beta version suggests that ONCOX1 is a membrane protein with 8 transmembrane helices(TM). Transmembrane helices were found in the positions 29-53,72-95, 126-145, 152-171, 192-211, 218-237, 258-282 and 289-306 as showed in table 1. The objective of this TM search step was to identify and map out regions of transmembrane helices to confirm our sequence database based hypothesis of the putative sequence being identified as a cytochrome $\mathrm{c}$ oxidase subunit I. Cythochrome $c$ oxidases are known to have these transmembrane regions and the identification of these regions served as a confirmatory step in gauging the validity of the predicted structure (Mohamed et al., 2003). The observation from the transmembrane prediction step is consistent with the subunit I of most other haem copper oxidases and acts as confirmatory data for correctness of the protein fold generated by the analysis program.

A final taxonomic system for the animal kingdom will probably include at least 10 million species partitioned among more than a million genera (Paul et al., 2003). Given such high diversity, there is a growing realization that it is critical to seek technological assistance for its initial description and its subsequent recognition (Godfray 2002; Blaxter 2003). Recent investigations have suggested the feasibility of creating identification systems reliant on the analysis of sequence diversity in small segments of DNA (Tautz et al. 2003). Hebert et al. (2003) focused this discussion by proposing that a DNA barcoding system for animal life could be based upon sequence diversity in cytochrome $c$

Table 1. Analysis of COX1 transmembrane amino acid sequence (SOSUI dumbbell server)

\begin{tabular}{cccccc}
\hline No. & N terminal & transmembrane region & C terminal & type & length \\
\hline 1 & 31 & IFSLHLAGVSSILGAINFITTII & 53 & Secondary & 23 \\
\hline 2 & 73 & LITAVLLLLSLPVLAAGITILLT & 95 & Primary & 23 \\
\hline 3 & 126 & VYILILPGFGIISHIVAYYAG & 146 & Primary & 21 \\
\hline 4 & 153 & YMGMVWAMMAIGLLGFIVAHHMF & 175 & Primary & 23 \\
\hline 5 & 188 & TSATIIIAIPTGVKVFSLATLHG & 210 & Secondary & 23 \\
\hline 6 & 219 & LALGFIFLFTVGGLTGIVLANSS & 241 & Primary & 23 \\
\hline 7 & 257 & HYVLSIGAVFAIVAGFVHFPLFS & 279 & Primary & 23 \\
\hline 8 & 286 & TTKIHFGVMFIGVNLTFFPHISW & 308 & Secondary & 23 \\
\hline
\end{tabular}




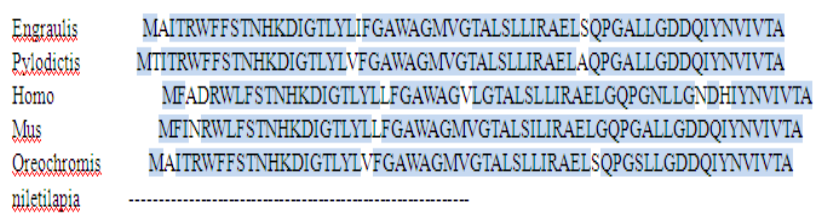

Engraulis

Pvilodictis

Homo

Mus

Oreochromis

niletilapia

Engraulis

Pylodictis

Homo

Nus

Orechromis

niletilapia

Engraulis

Pylodictis

Homo

Mus

Oreochromis

niletiliania

Engraulis

Pylodictis

Homo

Mus

Oreochromis

niletilapia

Engraulis

Pylodictis

Homo

Nus

Oreochromis

niletilapia

Engraulis

Pylodictis

Homo

Nus

Oreochromis

niletilapia

Engraulis

Pylodictis

Homo

Mus

Oreochromis

niletilapia

Engraulis

Pylodictis

Homo

Nus

Oreochromis

niletilapia

HAFVMFFMVMPILIGGFGNWLVPLMGGAPDMAFPRMNMSFILLPPSFLLLLASSGVEA HAFVMFFMVIPIMGGFGNILVPLMGGAPDMAFPRIANMSFILLPPSFLLLLASSGVEA HAFVMIFFMVMPIMGGGGNWUVPLMGAPDMAFPRMNNMSFWLLPPSLLLLLASAMVEA HAFVMFFMVMPMMGGFGNWLVPLMGAPDMAFPRINNMSFWLPPSFLLLLASSMVEA HAFVMFFMVMPIMIGGFNTLIPLMGGAPDMAFPRINNMISFWLLPPSFLLLASSGVEA

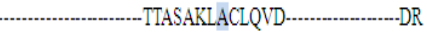

GAGTGWTVYPPLAGNLAHAGASVDITIFSLHLAGISSILGAINFITTIINMKPPAISQYQ GAGTGWTVYPPLAGNLAHAGASVDLTIFSLHLAGVSSILGAINFITTIINMKPPAISQYQ GAGTGWTVYPPLAGNYSHPGASVDITIFSLHLAGVSSILGAINFITTINMKPPAMTQYQ GAGTGWTVYPPLAGNLAHAGASVDLTIFSLHLAGVSSILGAINFITTIINMKPPAMTQYQ GAGTGWTVYPPLAGNLAHAGPSVLIIFSLHLAGVSILGAINFITTINMKPPAISQYQ GRGRG---.--.-THAGPSVDLTIFSLHLAGVSSILGAINFITTIINMKPPAISQYQ

*** $\quad * * * * * * * * * * * * * * * * * * * * * * * * * * * * * * * * * * * * * * * * *$

TPLFVWAVLITAVLLLLSLPVLAAGITMLLDRNLNTTFFDPAGGDPILYQHLFWFFGH TPLFVTVAGLITAVLLLLSLPVLAAGITMLIDRNLNTTFFPAGGGDPILYQHLFWFFGT TPLFVWSVITAVLLLLSLPVLAAGITMLLTDRNLNTTFFDAGGGDPILYQHLSWFFGH TPLFVWSVLITAVLLLLSLPVLAAGITMLIDRNLNTTFFDPAGGGDPIYQHLFWFFGH TPLFVWSVLITAVLLLLSLPVLAAGITMLLTDRNLNTTFFDPAGGGDPILYQHLFWFFGH TPLFVWSVLITAVLLLLSLPVLAAGITLLTDRNLNTTFFDPAGGGDPILYQHLF-FFGH

PEVYILILPGFGMSHIVAYYAGKKEPFGIMGMNTAMMAIGLLGFIVWAHHMFTVGMDVD QSMY-LILPGFGMSHIVAYYAGKKEPFGYMGMVWAMMAIGLLGFIVWAHHMFTVGMDVD PEVYILILPGFGMISHVTYYSGKKEPFGYMGMVTAMMSIGFLGFIVTWAHHIFTVGMDVD PEVYILILPGFGIISHVVTYYSGKKEPFGYMGMVWAIMIIGFLGIVWAHHMFTVGLDVD PEVYILILPGFGMSHIVAYYAGKKEPFGYMGMVWAMMAIGLLGFIVWAHHMFTVGMDVD PEVYILILPGFGIISHIVAYYAGKKEPFGYMGMVTAMMAIGLLGFIV-AHHMFTVGMDVD

TRAYFTSATMIAIPTGVKVFSWLATLHGGAIKWETPMLWALGFIFLFTVGGLTGIVLAN TRAYFTSATMIAIPTGVKVFSWLATLHGGSIKWETPLLWALGFIFLFTVGGLTGIVLAN TRAYFTSATMIAIPTGVKVFSWLATLHGSNMKWSAAVLWALGFIFLFTVGGLTGIVLAN TRAYFTSATMIAIPTGVKVFSWLATLHGGNIKWSPAMWALGFIFLFTVGGLTGIVLSN TRAYFTSATMIAIPTGVKVFSWLATLHGGAIKWETPLLWALGFIFLFTVGGLTGIVLAN TRAYFTSATIIIAIPTGVKVFS-LATLHGGAIKETP--LLALGFIFLFTVGGLTGIVLAN

SSLDIVLHDTYYVVAHFHYVLSMGAVFAIVAGFVHWFPLFTGYTLHSTWTKIHFGVMFVG SSLDIVLHDTYYVVAHFHYVLSMGAVFAIMGAFVHWFPLFTGYTMHDTWTKIHFGTMFVG SSLDIVLHDTYYVVAHFHYVISMGAVFAIMGGFIHWFPLFGYTLDQTYAKIHFAIMFIG SSLDIVLHDTYYVVAHFHYVLSMGAVFAIMAGFVHWFPLFSGFTLDDTWAKAHFAIMFVG SSLDIMLHDTYYVVAHFHYVLSMGAVFAIVAGFVHWFPLFSGYTLHDTWTKIHFGVMFVG SSLDIMLHDTYYVVAHFHYVLSIGAVFAIVAGFVH-FPLFSGYTLHDT-TKIHFGVMFIG

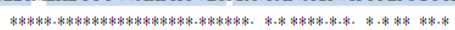

VNLTFFPQHFLGLAGMPRRYSDYPDAYT--LWNTVSSIGSLISLVAVIMFLFIIWEAFAA VNIFFPQHFLGLAGMPRRYSDYPDAYS--LWNIISSIGSLVSLVAVVMFLYILWEAFTA VNLTFFPQHFLGLSGMPRRYSDYPDAYT--TWNILSSVGSFISLTAVMLMFMIWEAFAS VNMTFFPQHFLGLSGMPRRYSDYPDAYT--TWNTVSSMGSFISLTAVLIMFMIWEAFAS VNLTFFPQHFLGLAGMPRRYFRLPRRLHPLKHNLFYWLNFNSQRGIMCFIYYIEKHLPL VNLIFFPHISW-...-...-DWQECFVG-..-TCPAAARVLRIPGYRARSYHGSKLFSG *******:

KREVASVELTINVEWLHGCPPPYHTFEEPAFVQVK KREVLSVELTSTNVEWLHGCPPPYHTFEEPAFVQVRTI

KRKVTIOTEPSIOTEITYCCPPPYHTFEEPIIVKSKREVMSVSYASTNLEWLHGCPPPYHTFEEPTVVKVK NEKVLSVELTATNVEWLHGCPPPYHTFEEPAFVQVQQAWLDYGKSATTPSKS

Figure 2. The alignment of COX1 deduced amino acid sequences of from Engraulis japonicas; Pylodictis olivaris; Homo sapiens; Mus musculus; Oreochromis mossambicus and Oreochromis niloticus (accession nos. NP 203729; AAL91550; BAA07292; CAD54434; YP 272017 and GE647 880 respectively). Identical amino acids are indicated with an asterisk, similar amino acids are shaded. Dashes are gaps generated by alignment

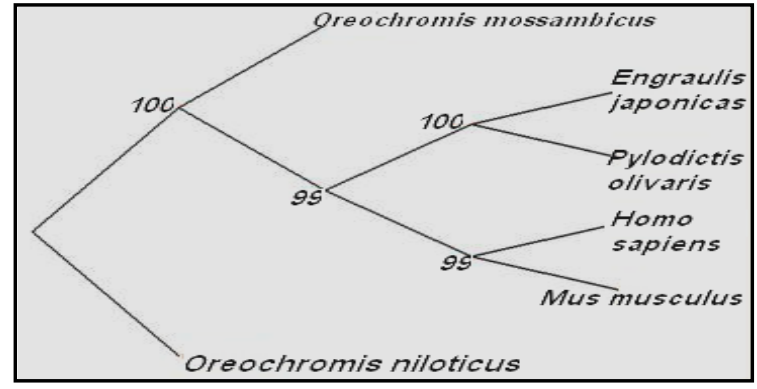

Figure 3. phylogenetic distance tree showing the relationship among the COX1 from different vertebrates

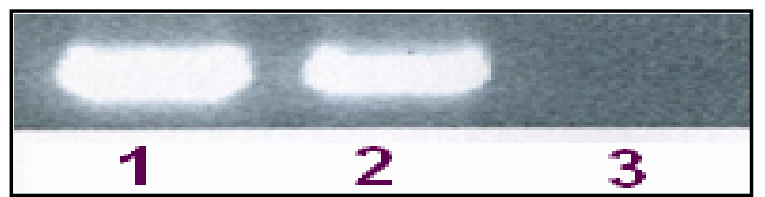

Figure 4. Tissue specific expression revealed by RT-PCR in Oreochromis niloticus; $1=\beta$ actin $2=$ =immunized fish, $3=$ unimmunized fish

Paul et al., 2003 in their study on COX1 divergences among closely related species indicated that an identification system for animal life based on the COI gene will be highly effective, although COXI divergences appear too low to regularly enable species diagnosis within the cnidarians, generic-level identifications in these organisms remain a prospect, as their study has established that species-level identifications are ordinarily achieved, COI analysis actually provides a taxonomic system that is chasing the last digit of animal diversity.

The mRNA expression of mixed tissues of $F$. columnare immunized $O$. niloticus indicated that the COX1 enzyme coding gene was highly expressed in the immunized in contrast to unimmunized fish, thus it is suggested to be included in the immune response against $F$. columnare.

Cytochrome $c$, which is a component of the mitochondrial electron transfer chain releases from the mitochondria in response to specific apoptotic stimuli (Wang X., 2001). It is initiates caspase activation when released from mitochondria during apoptosis (Liu et al.1996), Skulachev V.P.(1998) in his study on apoptosis has revealed that cytochrome $\mathrm{c}$ is a pro-apoptotic factor. It is released from its places on the outer surface of the inner mitochondrial membrane at early steps of apoptosis and, combining with some cytosolic proteins, activates conversion of the latent apoptosis-promoting protease pro-caspase- 9 to its active form. Thus from this investigation, it is suggested that COX1 may be included in the immune response against bacterial infection, the higher level of expression may also imply its role as an apoptotic inducer.

\section{Conclusions}

It could be concluded that killed $F$. columnarae did stimulate the immune response in the host fish, tilapia, some immune genes could be identified and characterized, one of these genes is COX1, which may have a role and included in 
the immune response to bacterial infection, thus the present study provides some information for further research on the structure of COX1 gene as an immune gene in relation to bacterial infection.

\section{REFERENCES}

[1] Altschul, S.F.; Thomas, L.M.; Alejandro, A.S.; Jinghui Z.; Zheng Z.; Webb, M. and David, J.L.1997.Gapped BLAST and PSI-BLAST: a new generation of protein database search programs. Nucleic Acids Research,September, 25( 17): $3389-3402$

[2] Blaxter, M. 2003. Counting angels with DNA. Nature 421:122-124

[3] Ettickan Boopathi, Nibedita Lenka, Subbuswamy K. Prabu , Ji-Kang Fang, Frank Wilkinson, Michael Atchison, Agata Giallongo, and Narayan G. Avadhani (2004). Regulation of Murine Cytochrome c Oxidase $\mathrm{Vb}$ Gene Expression during Myogenesis. J. Biol. Chem., Vol. 279, Issue 34:35242-35254

[4] Godfray, H. C. J. 2002. Challenges for taxonomy. Nature 417:17-19

[5] Hebert, P. D. N., Cywinska, A., Ball, S. L. \& deWaard, J. R. 2003. Biological identifications through DNA barcodes. Proc. R. Soc. Lond. B 270: 313-322
[6] Lee, I., Bender, E., Arnold, S., and Kadenbach, B. 2001. Biol. Chem. 382: 1629-1636. Lee, I., Bender, E., and Kadenbach, B. 2003. Mol. Cell. Biochem. 234:63-70

[7] Liu X, Kim CN, Yang J, Jemmerson R, Wang X.1996. Induction of apoptotic program in cell-free extracts: requirement for dATP and cytochrome c. J. Cell.12; 86(1):147-57

[8] Mohamed .R; Raih, M.R.; Sailan A.T.; Zamrod Z.; Embi M.N. 2003. A predicted structure of the cytochrome c oxidase from Burkholderia Pseudomallei. J. Boitec. 6: 17-28

[9] Paul D. N. Hebert*, Sujeevan Ratnasingham and Jeremy R. deWaard.2003. Barcoding animal life:cytochrome c oxidase subunit 1 divergences among closely related species. Proc. R. Soc. Lond. B (Suppl.) 270:S96-S99

[10] Skulachev V.P. 1998. Bioenergetic aspects of apoptosis, necrosis and mitoptosis. J. APOPTOSIS 11 (4): 473-485

[11] Tautz, D., Arctander, P., Minelli, A., Thomas, R. H. \& Vogler, A. P. 2003. A plea for DNA taxonomy. Trends Ecol. Evol. $18: 70-74$

[12] Thompson, J.D.; Higgins, D.G. and Gibson, T.J. 1994. CLUSTAL W: improving the sensitivity of progressive multiple sequence alignment through sequence weighting, positions-specific gap penalties and weight matrix choice. J.Nucleic Acids Research. 22: 4673-4680

[13] Vijayasarthy, C., Damle, S., Prabu, S. K., Otto, C. M., and Avadhani, N. G. 2003.Eur. J. Biochem. 270: 871-879

[14] Wang, X. 2001.The expanding role of mitochondria in apoptosis. J. Genes Dev. 15:29-22 